Supporting Information

\title{
Sustainable Lignin-Based Coatings Doped with Titanium Dioxide Nanocomposites Exhibit Synergistic Microbicidal and UV Blocking Performance toward Personal Protective Equipment
}

Ravneet Kaur, ${ }^{a, b}$ Neeraj S. Thakur, ${ }^{a}$ Sanjam Chandna, ${ }^{a, b}$ and Jayeeta Bhaumik ${ }^{a, *}$

${ }^{a}$ Center of Innovative and Applied Bioprocessing (CIAB),

Department of Biotechnology (DBT), Government of India,

Sector 81 (Knowledge City), S.A.S. Nagar 140306, Punjab, India

${ }^{b}$ Department of Microbial Biotechnology, Panjab University, South Campus, Sector 25, Chandigarh 160036, India

*Corresponding author's email: jayeeta@ciab.res.in,jbhaumi@gmail.com 


\section{Table of Contents}

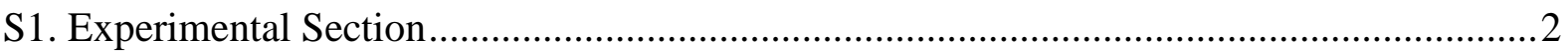

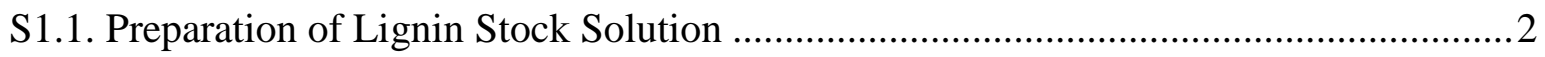

S1.1.1. Commercial Alkali Lignin: ..............................................................................

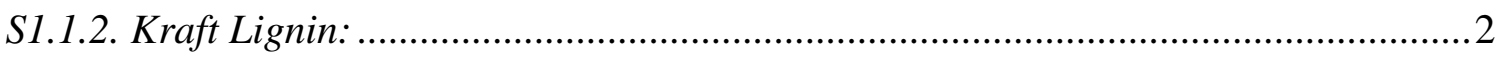

S2. Characterization of Nanocomposites and coatings ...................................................2

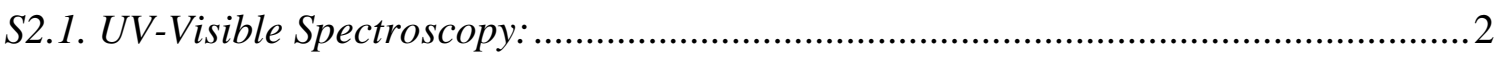

S2.2. Particle Size Analysis: ........................................................................................... 3

S2.3. Scanning Electron Microscopy (SEM): ............................................................ 5

S2.4. High Resolution-Transmission Electron Microscopy (HR-TEM) and Electron Dispersive X-Ray (EDX) Spectroscopy: ........................................................................

S2.5. Powder X-Ray Diffraction (XRD) Analysis: ......................................................... 6

S2.6. Fourier Transform Infrared (FTIR) Spectroscopy: ................................................6

S2.7. Thermogravimetric Analysis (TGA) of Coatings: ....................................................

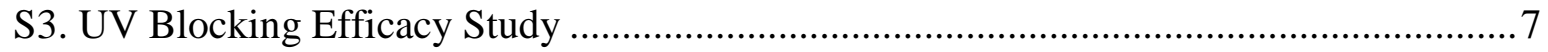

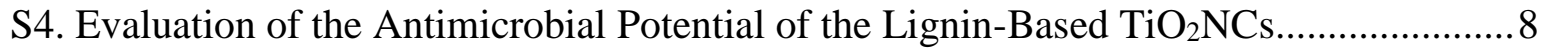

\section{S1. Experimental Section}

\section{S1.1. Preparation of Lignin Stock Solution}

S1.1.1. Commercial Alkali Lignin: Lignin stock solution (16 $\mathrm{mg} / \mathrm{mL})$ was prepared by dissolving lignin powder directly in ethanol. The solution was stirred using a magnetic stirrer for $30 \mathrm{~min}$ at $25^{\circ} \mathrm{C}$ for homogenous mixing.

S1.1.2. Kraft Lignin: Kraft lignin was crushed using a pestle mortar to obtain a fine powder. The powder $(16 \mathrm{mg})$ was then dissolved in absolute ethanol $(1 \mathrm{~mL})$. To this solution, $2 \mathrm{M}$ aqueous $\mathrm{NaOH}$ was added dropwise till the homogenous solution was obtained. The resulting solution was then stirred at $60^{\circ} \mathrm{C}$ for $2 \mathrm{~h}$.

\section{S2. Characterization of Nanocomposites and coatings}

S2.1. $U$ V-Visible Spectroscopy: For UV-visible spectroscopy analysis, a sample solution of

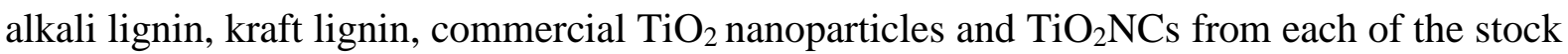
solution and reaction mixtures were diluted with an equal volume of ethanol. The absorption spectra were then recorded $(200-650 \mathrm{~nm})$ using a UV-Vis spectrophotometer (Table S1). 
S2.2. Particle Size Analysis: The lignin-based $\mathrm{TiO}_{2} \mathrm{NCs}$ were suspended in ethanol and sonicated for $10 \mathrm{~min}$ prior to the analysis. Particle size analysis of each of the nanocomposites suspension was performed using a Zetasizer (Table S1, Figure S1 a-d).

Table S1. Characterization data of the nanocomposites:

\begin{tabular}{|l|c|c|}
\hline Nanocomposite type & $\begin{array}{l}\text { UV-vis absorption } \\
\text { maxima }(\mathbf{n m})\end{array}$ & $\begin{array}{l}\text { Zeta potential } \\
(\mathbf{m V})\end{array}$ \\
\hline $\begin{array}{l}\mathrm{TiO}_{2} \mathrm{AL} \\
\text { nanocomposites }\end{array}$ & 300 & -39.3 \\
\hline $\begin{array}{l}\mathrm{TiO}_{2} \mathrm{KL} \\
\text { nanocomposites }\end{array}$ & $300-350$ & -32 \\
\hline Commercial $\mathrm{TiO}_{2} \mathrm{NPs}$ & & 0.862 \\
\hline
\end{tabular}




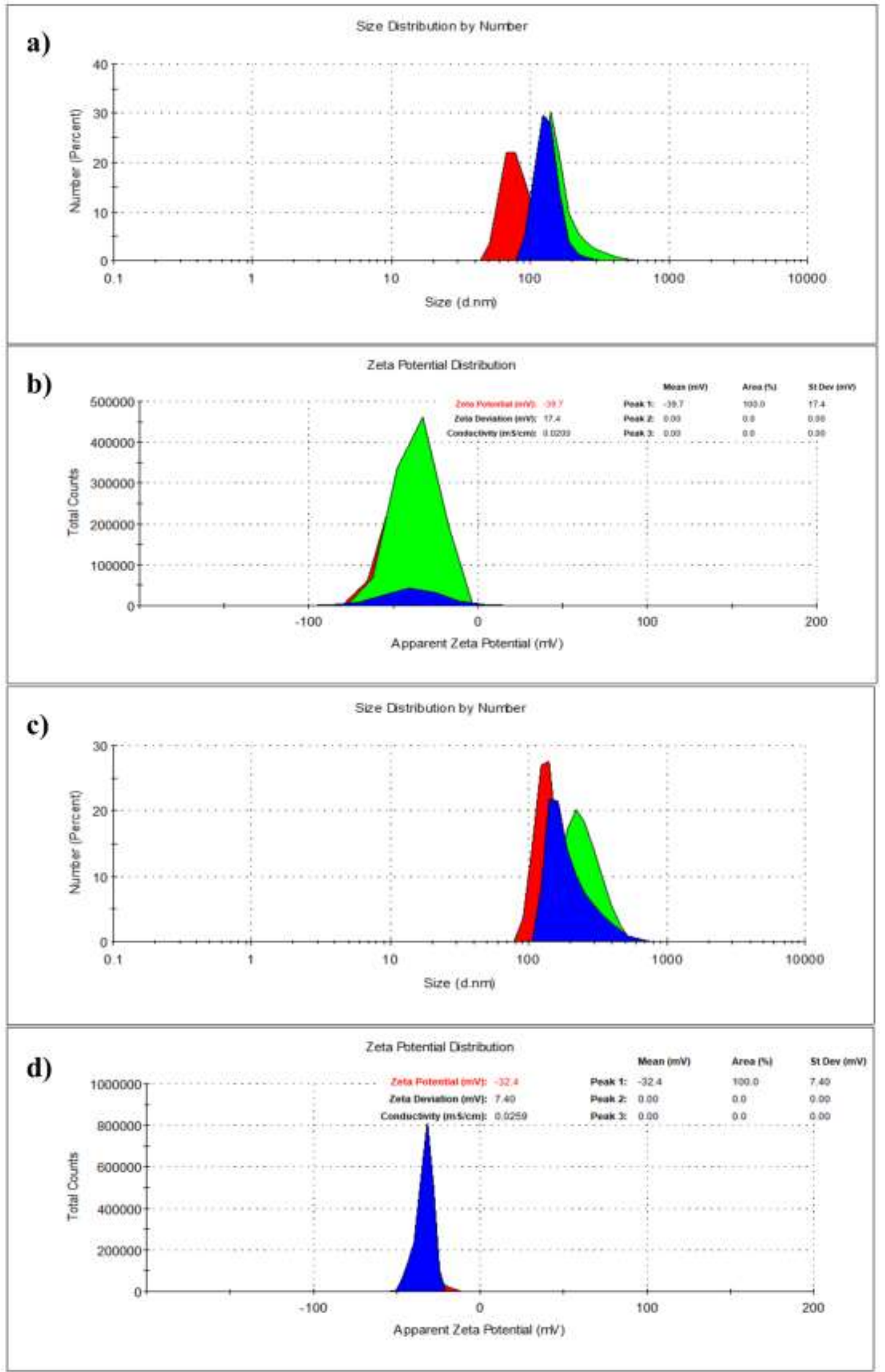

Figure S1. (a),(c) The size distribution and (b),(d) zeta potential graphs of $\mathrm{TiO}_{2} \mathrm{AL}$ and $\mathrm{TiO}_{2} \mathrm{KL}$ nanocomposites, respectively. 


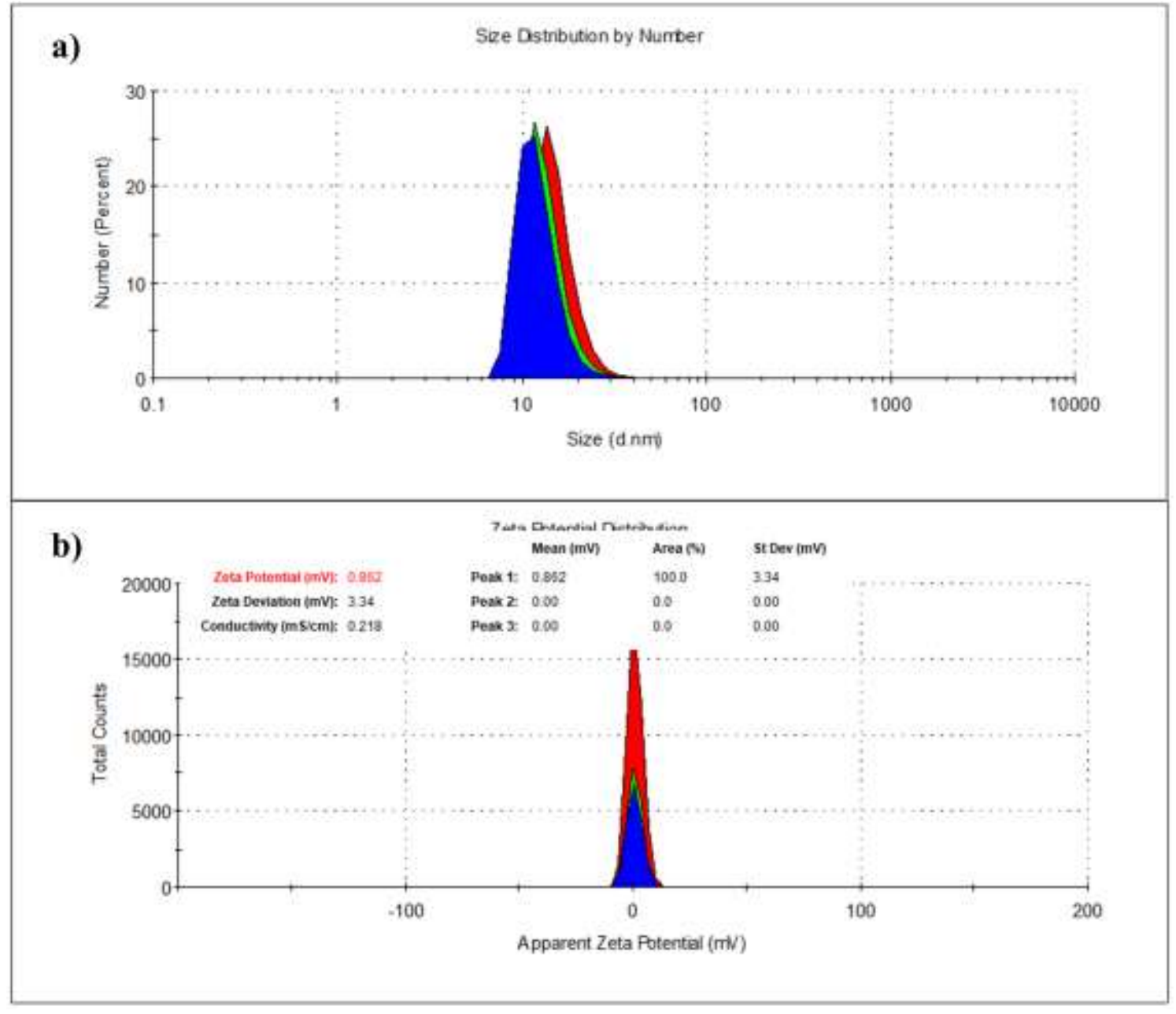

Figure S2. (a) The size distribution and (b) zeta potential graphs of commercial $\mathrm{TiO}_{2}$ nanoparticles.

S2.3. Scanning Electron Microscopy (SEM): The shape and size of the nanocomposites were further analyzed using scanning electron microscopy (SEM), For this, the dried nanocomposite sample was placed on a carbon tape, coated with gold, and observed under the SEM.

\section{S2.4. High Resolution-Transmission Electron Microscopy (HR-TEM) and Electron}

Dispersive X-Ray (EDX) Spectroscopy: The size, shape, and composition of nanocomposites were analyzed using HR-TEM and EDX analysis respectively. Nanocomposites were suspended in ethanol and sonicated for 20 min prior to placing each sample on a copper grid. The sample was then deposited and dried on top of the grid followed by analysis under TEM. 

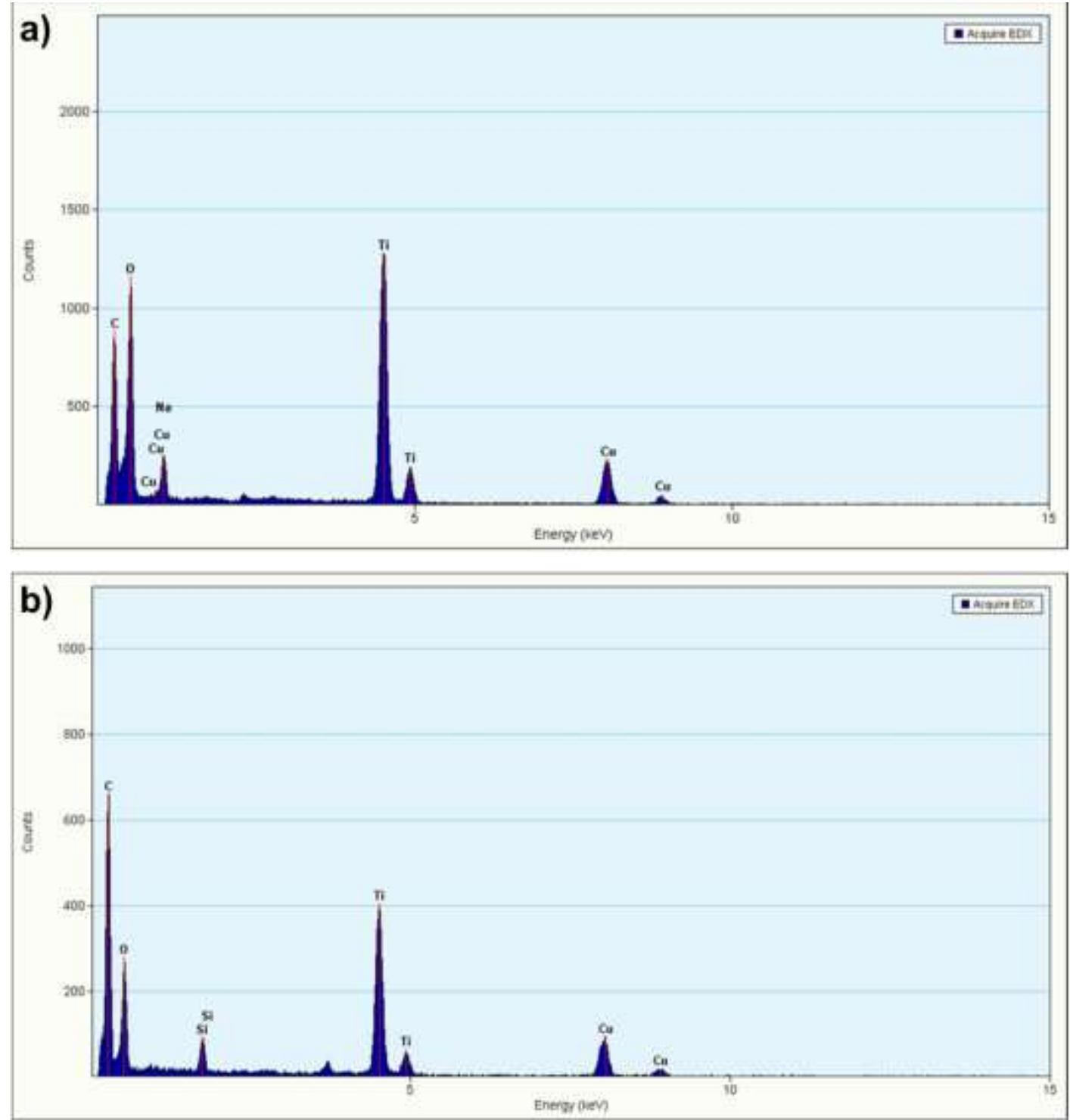

Figure S3. The electron dispersive X-Ray (EDX) spectroscopy analysis of (a) $\mathrm{TiO}_{2} \mathrm{AL}$ and (b) $\mathrm{TiO}_{2} \mathrm{KL}$ nanocomposites, respectively.

S2.5. Powder X-Ray Diffraction (XRD) Analysis: The $\mathrm{TiO}_{2} \mathrm{NCs}$ powder samples were tightly packed into the sample holders. The X-ray diffraction patterns of the ZnONCs samples were then obtained by using a fully automatic high-resolution powder X-ray diffractometer system with $2 \theta=2-80^{\circ}$.

S2.6. Fourier Transform Infrared (FTIR) Spectroscopy: The presence of functional groups on the surface of $\mathrm{TiO}_{2} \mathrm{NCs}$ were analyzed by FTIR spectroscopy analysis. Each sample $(5 \mathrm{mg})$ in dried form was placed on the sample holder and FTIR spectra were recorded on an FTIR spectrometer using a self-supported pellet technique (Figure S2 and Figure S3). 


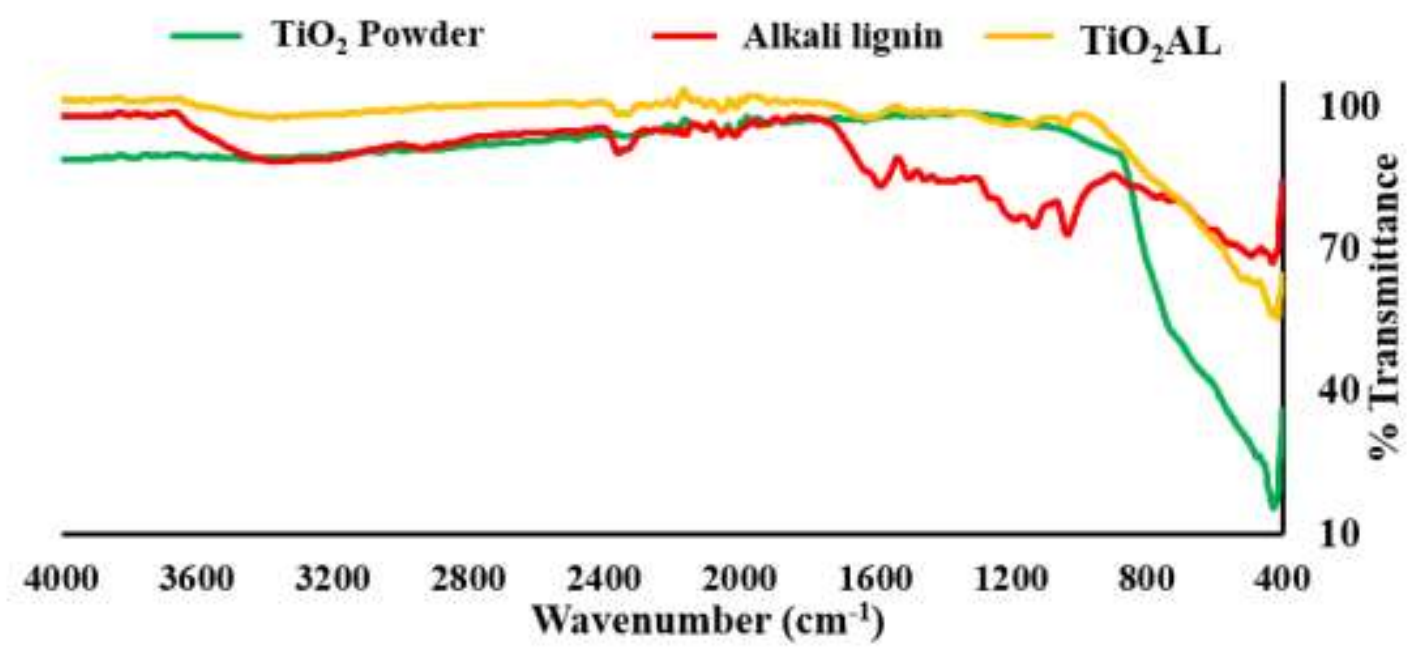

Figure S4. FTIR spectra of alkali lignin, $\mathrm{TiO}_{2}$ powder, and $\mathrm{TiO}_{2} \mathrm{AL}$ nanocomposites

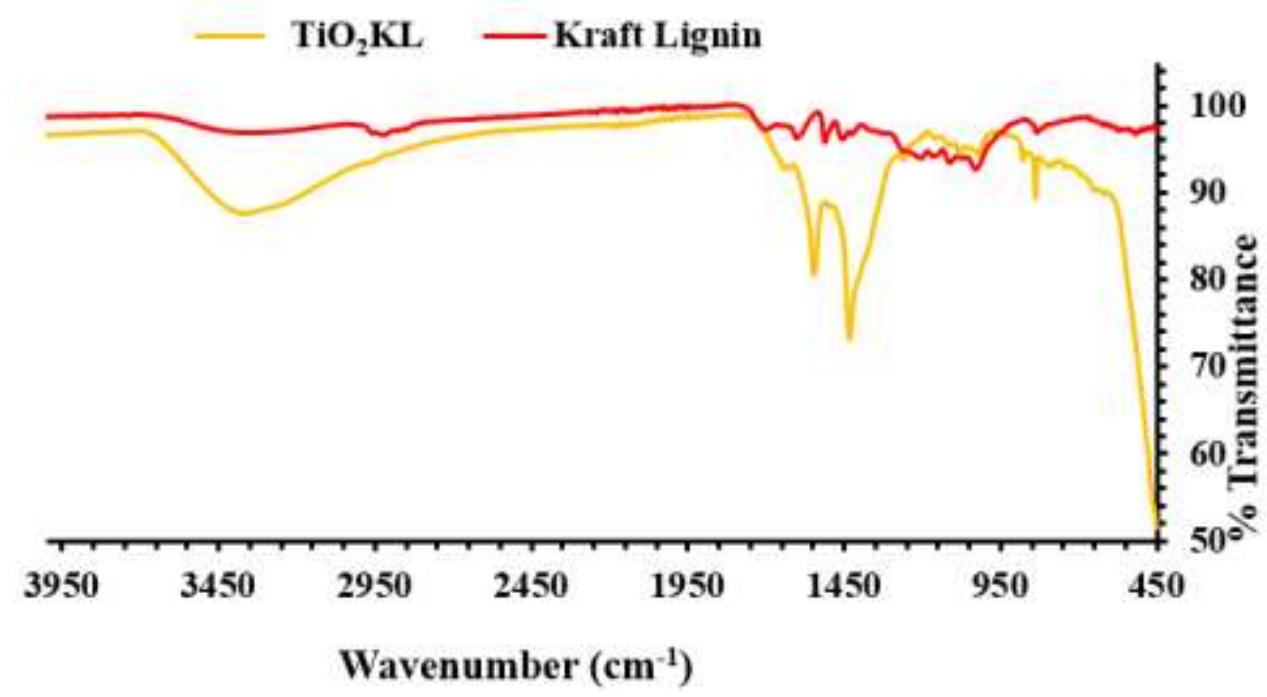

Figure S5. FTIR spectra of kraft lignin and $\mathrm{TiO}_{2} \mathrm{KL}$ nanocomposites.

S2.7. Thermogravimetric Analysis (TGA) of Coatings: The TGA of coatings were performed on Perkin Elmer STA 8000 simultaneous thermal analyzer. $4 \mathrm{mg}$ of powdered dried coating was placed on an aluminium crucible and heated in the range $25{ }^{\circ} \mathrm{C}-800{ }^{\circ} \mathrm{C}$ at a heating speed of $10{ }^{\circ} \mathrm{C} / \mathrm{min}$ in the nitrogen atmosphere.

\section{S3. UV Blocking Efficacy Study}

To evaluate the UV protection efficiency, the synthesized nanocomposites were dissolved in ethanol (final concentration $300 \mu \mathrm{g} / \mathrm{mL}$ ) and sonicated for $10 \mathrm{~min}$. UV transmittance analysis 
was performed in the range of 280-400 nm for all the samples. Experiments were conducted in triplicates.

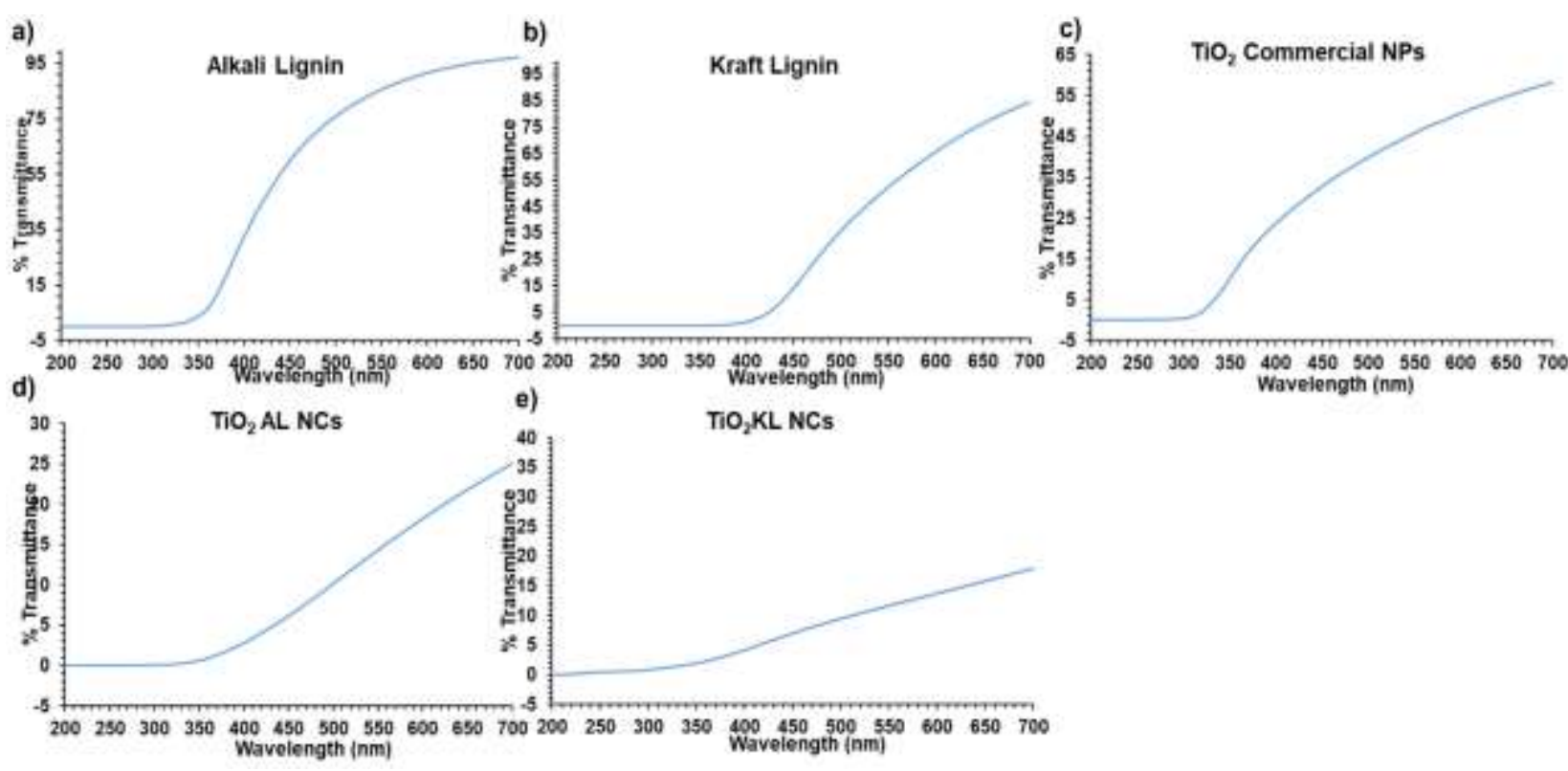

Figure S6. UV-Vis spectra indicating \% transmittance of the synthesized nanocomposites and different lignin: a) alkali lignin, b) kraft lignin, c) $\mathrm{TiO}_{2} \mathrm{NP}$ commercial, d) $\mathrm{TiO}_{2} \mathrm{AL}$ nanocomposites, and e) $\mathrm{TiO}_{2} \mathrm{KL}$ nanocomposites.

\section{S4. Evaluation of the Antimicrobial Potential of the Lignin-Based $\mathrm{TiO}_{2} \mathrm{NCs}$}
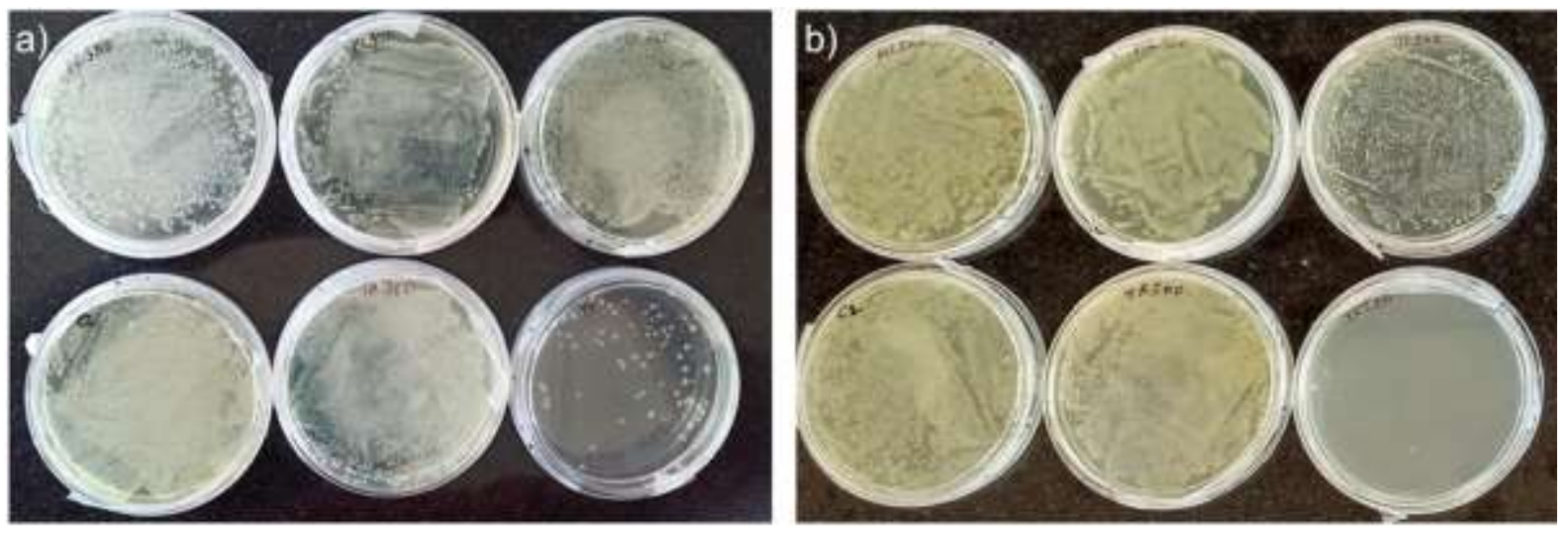

Figure S7. Antimicrobial activity of the $\mathrm{TiO}_{2} \mathrm{NCs}$ against E. coli (a) at $350 \mu \mathrm{g} / \mathrm{mL}$ concentration and (b) at $500 \mu \mathrm{g} / \mathrm{mL}$ concentration. 

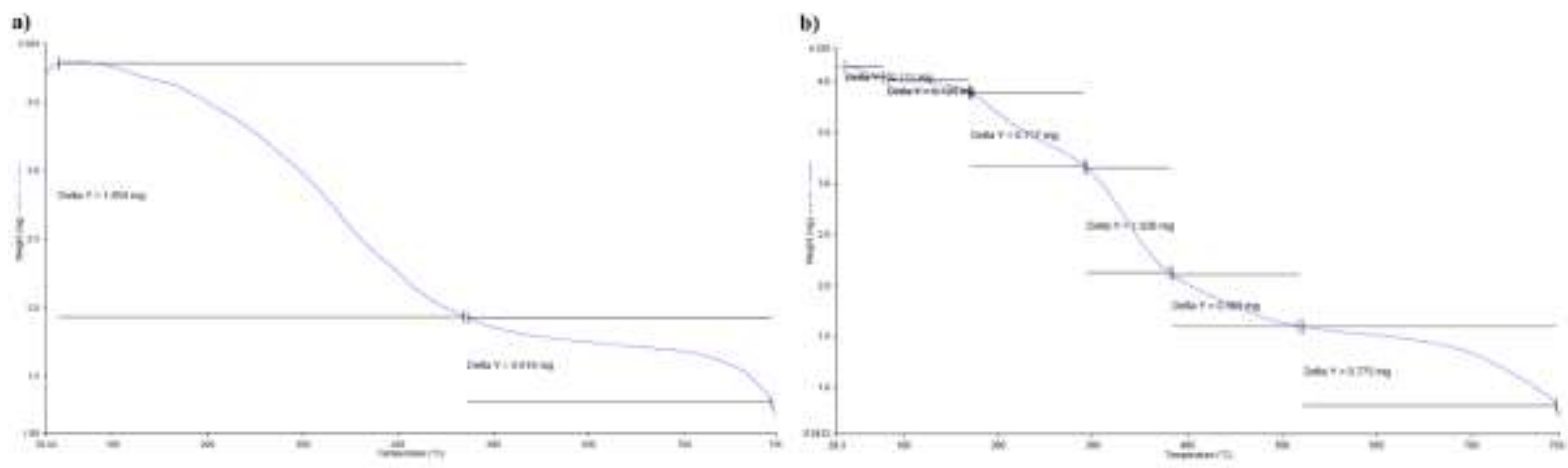

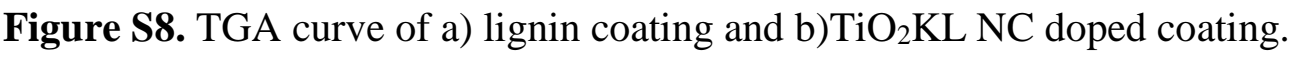

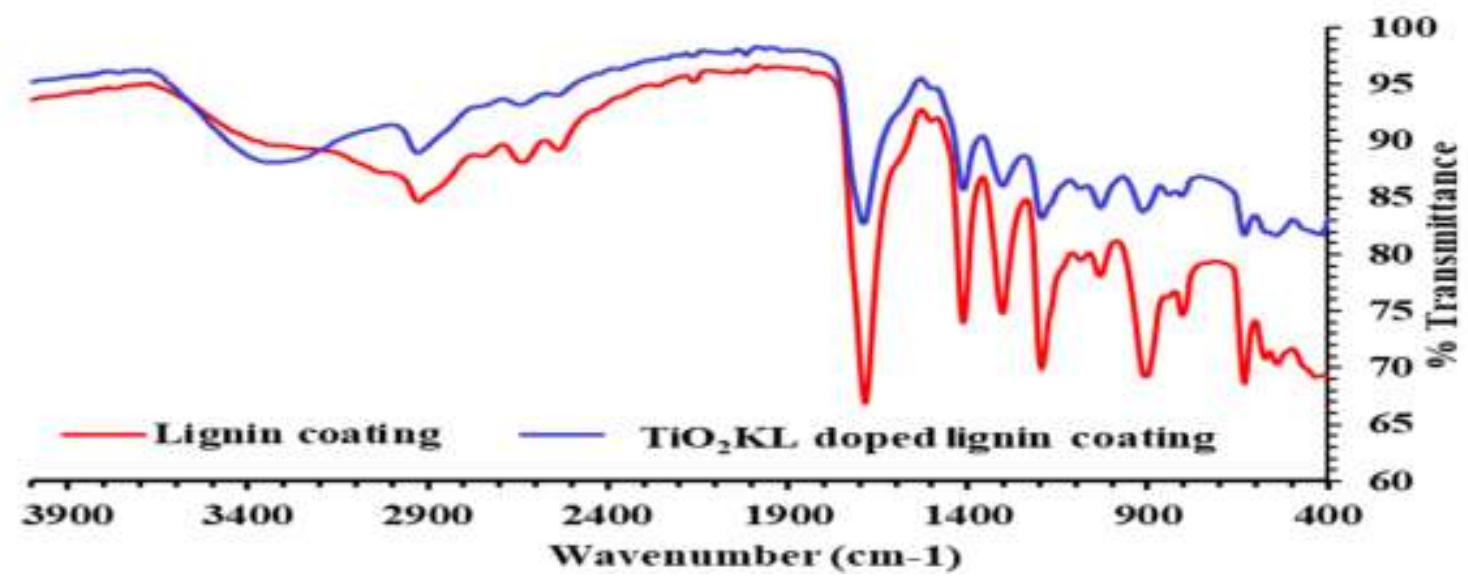

Figure S9. FTIR spectra of the lignin coating and $\mathrm{TiO}_{2} \mathrm{KL} \mathrm{NC}$ doped lignin coating. 